\title{
Understanding the Mechanism of Direct Activation of AMP-Kinase: Towards a Fine Allosteric Tuning of the Kinase Activity ${ }^{\dagger}$
}

\author{
Elnaz Aledavood ${ }^{1, *}$, Gleiciane Moraes ${ }^{2}$, Jeronimo Lameira ${ }^{2}$, Ana Castro ${ }^{3}$, Francisco Javier Luque ${ }^{1}$ \\ and Carolina Estarellas 1 \\ 1 Department of Nutrition, Food Science and Gastronomy, Faculty of Pharmacy and Food Sciences, Institute \\ of Biomedicina (IBUB) and Institute of Theoretical and Computational Chemistry (IQTCUB), University of \\ Barcelona, Santa Coloma de Gramenet 08921, Spain \\ 2 Faculdade de Ciências Naturais, Campus Universitário do Marajó-Breves, Universidade Federal do Pará \\ (CUMB-UFPA), 68000-000 Breves, Brazil \\ 3 Instituto de Química Médica, Consejo Superior de Investigaciones Científicas (IQM-CSIC), 28006 Madrid, \\ Spain \\ * Correspondence: el.aledavood@ub.edu \\ + Presented at the 2nd Molecules Medicinal Chemistry Symposium (MMCS): Facing Novel Challenges in \\ Drug Discovery, Barcelona, Spain, 15-17 May 2019.
}

Published: 7 August 2019

Keywords: AMP-kinase; Direct activator; Molecular dynamics simulations

This research deals with the regulation of the AMPK activity by direct activators, such as compound A-769662. AMPK is a key enzyme to maintain the cellular energy homeostasis, as it regulates the levels of ATP, being an important target to metabolic diseases like obesity or diabetes MT2. It is formed by 3 subunits $\alpha, \beta$, and $\gamma$. The activation mechanism of A-769662 is of particular interest, because it activates AMPK independently of $\alpha$-Thr172 phosphorylation, the $\beta$-Ser108 being phosphorylated. Under these circumstances, binding of A-769662 enhances the AMPK activity up to $>90$-fold (PDB 4CFF) [1-3].

We have recently studied the chain of events implicated in the binding of this ligand to the activating binding site, which is located between the $\alpha$ and $\beta$ subunits of AMPK. MD simulations of AMPK were run for apo, holo, and holo+ ATP systems. For each system, we ran three independent MD simulations up to $1 \mu \mathrm{s}$. The impact of the activator binding was studied by different analysis, such as essential dynamics and evaluation of conformational entropies, among others [4].

We concluded that A-769662 acts as a molecular glue, making an effective connection between $\beta$ - and $\alpha$-subunits that pre-organizes the ATP-binding site, favouring the binding of ATP, and explaining the increase of the AMPK activity. These findings pave the way to explore the structural features that underline the different sensitivity of AMPK isoforms to A-769662, i.e., try to discern why A-769662 is only active in the $\alpha 2 \beta 1 \gamma 1$ isoform, while other compounds are active with isoform $\beta 2$.

\section{References}

1. Xiao, B.; Sanders, M.J.; Carmena, D.; Bright, N.J.; Haire, L.F.; Underwood, E.; Patel, B.R.; Heath, R.B.; Walker, P.A.; Hallen, S.; et al. Structural basis of AMPK regulation by small molecule activators. Nat. Commun. 2013, 4, 3017.

2. Sanders, M.J.; Ali, Z.S.; Hegarty, B.D.; Heath, R.; Snowden, M.A.; Carling, D. Defining the mechanism of activation of AMP-activated protein kinase by the small molecule A-769662, a member of the thienopyridone family. J. Biol. Chem. 2007, 282, 32539-35248. 
3. Scott, J.W.; van Denderen, B.J.; Jorgensen, S.B.; Honeyman, J.E.; Steinberg, G.R.; Oakhill, J.S.; Iseli, T.J.; Koay, A.; Gooley, P.R.; Stapleton, D.; et al. Thienopyridone drugs are selective activators of AMP-activated protein kinase beta1-containing complexes. Chem. Biol. 2008, 15, 1220-1230.

4. Aledavood, E.; Moraes, G.; Lameira, J.; Castro, A.; Luque, F.J.; Estarellas, C. Understanding the mechanism of direct activation of AMP- kinase: Towards a fine allosteric tuning of the kinase activity. J. Chem. Inf. Model. 2019, 59, 2859-2870.

(C) 2019 by the authors. Licensee MDPI, Basel, Switzerland. This article is an open access article distributed under the terms and conditions of the Creative Commons Attribution (CC BY) license (http://creativecommons.org/licenses/by/4.0/). 